\title{
Boron isotope fractionation accompanying boron mineral formation from aqueous boric acid-sodium hydroxide solutions at $25^{\circ} \mathrm{C}$
}

\author{
TAKaO OI, JUNPEI Kato, TOMOKO OSSAKa \\ and HideTAKe KaKIHANA \\ Department of Chemistry, Sophia University, \\ 7-1 Kioicho, Chiyodaku, Tokyo 102, Japan
}

(Received November 22, 1990; Accepted October 31, 1991)

\begin{abstract}
A series of experiments was carried out in which boron minerals were precipitated from $\mathrm{pH}$ - and chemical composition-controlled solutions at $25^{\circ} \mathrm{C}$ and boron isotope fractionation accompanying the mineral deposition was measured. Borax, sassolite and sborgite were synthesized from aqueous boric acid-sodium hydroxide solutions. Borax was obtained from solutions with higher $\mathrm{pH}$ and sassolite from solutions with lower $\mathrm{pH}$, irrespective of the mole ratio of $\mathrm{B}$ and $\mathrm{Na}$ in the solution. The fractionation factor, $S$, defined as $S=\left({ }^{11} \mathrm{~B} /{ }^{10} \mathrm{~B}\right)_{\text {mineral }} /\left({ }^{11} \mathrm{~B} /{ }^{10} \mathrm{~B}\right)_{\text {solution }}$ increases with increasing the $\mathrm{pH}$ of the solution for both borax and sassolite. A cross-over point at which $S=1$ was found at about $\mathrm{pH}=9.5$ for borax, while $S$ was always larger than unity for sassolite. The present results of boron isotope fractionation are consistent with theoretical prediction of equilibrium isotope effects, although the experimental equilibrium constant of the boron isotope exchange reaction between $\mathrm{B}(\mathrm{OH})_{3}$ and $\mathrm{B}(\mathrm{OH})_{4}^{-}$at $25^{\circ} \mathrm{C}$ is larger than that theoretically predicted (1.03-1.05 compared to 1.0194).
\end{abstract}

\section{INTRODUCTION}

Variations in boron isotopic compositions in nature are of geochemical and cosmochemical importance. They are utilizable for studying nucleosynthetic mechanism at the early stage of the solar system and the galaxy (Ishikawa and Nakamura, 1989), and are also used for studying the sedimentary cycle of boron (Spivack et al., 1987), hydrothermal and geothermal processes (Spivack and Edmond, 1987), the interaction of magmas with sea water (Kanzaki et al., 1979; Nomura et al., 1982; Oi et al., 1991) and the genesis of ore deposits (Palmer and Slack, 1989; Slack et al., 1989). To make full use of boron isotopes as a tracer in natural systems, it is necessary to have a good understanding of boron isotope effects which occur at each step of boron reaction in nature.
In a previous paper (Oi et al., 1989), we showed that evaporite boron minerals with the same geologic origin but with different structural formulae have different boron isotopic compositions. That is, minerals with higher $\mathrm{BO}_{3} / \mathrm{BO}_{4}$ ratios (the ratio of the number of $\mathrm{BO}_{3}$ triangle units to the number of $\mathrm{BO}_{4}$ tetrahedron units in the structural formula of a mineral) have higher ${ }^{11} \mathrm{~B} /{ }^{10} \mathrm{~B}$ ratios. This observation is consistent with prediction from the theory of isotope effects based on the isotopic reduced partition function ratios (RPFRs) (Bigeleisen and Mayer, 1947). However, a quantitative approach is still required. The previous study showed that the type of mineral formed and its boron isotopic ratio are strongly dependent on the chemical composition and $\mathrm{pH}$ of original solution from which the mineral was deposited. Therefore, to elucidate quantitatively boron isotope fractionation in the 
boron mineral formation from boron-bearing solutions, we carried out a series of synthesis experiments with chemical composition- and $\mathrm{pH}-$ controlled boric acid-sodium hydroxide solutions. The boron isotopic ratios of solutions and minerals were then measured. In this paper, we report the results of these experiments and discuss the boron isotope fractionation accompanying boron mineral formation from aqueous solution.

\section{EXPERIMENTAL}

The experimental procedures are briefly as follows. A saturated boric acid solution was first prepared at $23^{\circ} \mathrm{C}$. To this solution was added sodium hydroxide so that the mole ratio of boron to sodium becomes $1: 1,1: 2$ or $2: 1$. The $\mathrm{pH}$ of the solution was then adjusted by $5 \mathrm{M}$ $\left(1 \mathrm{M}=1 \mathrm{~mol} / \mathrm{dm}^{3}\right) \mathrm{HCl}$ and then used as the initial solution of each experiment (Table 1). About $200 \mathrm{~cm}^{3}$ of this initial solution contained in a beaker was placed in a water bath temperature-controlled at $25 \pm 0.2^{\circ} \mathrm{C}$. While the beaker was in the bath, it was not shaken nor was the solution stirred, but the $\mathrm{pH}$ of the solution was monitored frequently. Minerals were precipitated from the solution by concentration of the solution due to water evaporation, without any artificial manipulation such as insertion of a seed crystal. Upon the mineral deposition, the $\mathrm{pH}$ of the solution phase was measured and the solid and the liquid phases were separated by suction filtration using a chilled glass filter. The precipitate was air-dried and the mineral phase was identified by X-ray powder diffraction using a Rigaku Denki X-ray spectrometer. The amounts of boron precipitated and remaining in solution were determined by conventional acid-base titration or by inductively coupled plasma atomic emission spectrometry.

The boron isotopic ratios of the solution and minerals were measured by the surface ionization method with a Varian MAT CH-5 mass spectrometer at Tokyo Institute of Technology. The details of mass spectrometry are given elsewhere
Table 1. The initial conditions of the solution phase

\begin{tabular}{ccccc}
\hline Run No. & pH & $\begin{array}{c}\text { B:Na } \\
\text { mole ratio }\end{array}$ & $\begin{array}{c}\text { B concn } \\
\left(\text { moldm }^{-3}\right)\end{array}$ & $\begin{array}{c}\text { Volume } \\
\left(\mathrm{cm}^{3}\right)\end{array}$ \\
\hline B17 & 11.52 & $1: 1$ & 0.885 & 199.3 \\
B08 & 11.01 & $1: 1$ & 0.812 & 203.6 \\
B18 & 11.01 & $1: 1$ & 0.880 & 200.7 \\
B09 & 10.01 & $1: 1$ & 0.785 & 211.1 \\
B10 & 9.01 & $1: 1$ & 0.761 & 217.6 \\
B23 & 8.01 & $1: 1$ & 0.851 & 223.3 \\
B25 & 8.00 & $1: 2$ & 0.680 & 252.0 \\
B24 & 7.01 & $1: 2$ & 0.775 & 226.0 \\
B27 & 8.99 & $2: 1$ & 0.851 & 202.3 \\
B29 & 7.00 & $2: 1$ & 0.809 & 212.5 \\
B30 & 6.00 & $2: 1$ & 0.797 & 215.8 \\
\hline
\end{tabular}

(Nomura et al., 1973; Oi et al., 1989). In brief, boron was extracted from liquid samples and purified by methyl borate distillation and ion-exchange. Sodium hydroxide was then added so that the mole ratio of $\mathrm{B}$ to $\mathrm{Na}$ became about 1:1.5. The resultant solution was loaded on a boat-shaped rhenium filament. The boron isotopic ratio was determined by measuring the height ratio of $\mathrm{Na}_{2}{ }^{10} \mathrm{BO}_{2}^{+}$and $\mathrm{Na}_{2}{ }^{11} \mathrm{BO}_{2}^{+}$peaks. In the case of solid samples, the samples were first dissolved in pure water and the subsequent procedure was the same as that for the liquid samples. The $95 \%$ confidence limit of measurement was typically about $\pm 0.2 \%$. Each sample was measured 2 or 3 times and the average was taken as the isotopic ratio of the sample (Nomura et al., 1973).

\section{RESUlTs}

Experimental results are summarized in Tables 2 and 3. It took about 2 days to 3 weeks to precipitate minerals. Any correlation was not found between the conditions of initial solutions and the time that elapsed before mineral deposition started (deposition time). For each experiment, the $\mathrm{pH}$ of the solution was fairly constant until the initiation of mineral precipitation. The $\mathrm{pH}$ of the solution after precipitation became slightly higher than that of the initial solution when the latter was above 10 but became slightly lower when the latter was below 9. The mole fraction of boron transferred from the solution 
Table 2. Experimental results other than isotopic data

\begin{tabular}{|c|c|c|c|c|c|c|}
\hline \multirow{2}{*}{$\begin{array}{l}\text { Run } \\
\text { No. }\end{array}$} & \multirow{2}{*}{$\begin{array}{c}\text { Deposition } \\
\text { time (h) }\end{array}$} & \multirow{2}{*}{$\begin{array}{c}\text { Approximate } \\
\text { Volume of water } \\
\text { evaporated } \\
\left(\mathrm{cm}^{3}\right)\end{array}$} & \multicolumn{2}{|c|}{ Solution phase } & \multicolumn{2}{|c|}{ Solid phase } \\
\hline & & & $\mathrm{pH}$ & $\begin{array}{c}\text { B conc. } \\
\left(\text { moldm }^{-3}\right)\end{array}$ & $\begin{array}{l}\text { Deposited } \\
\text { mineral }\end{array}$ & $\begin{array}{l}\text { Mole } \\
\text { fraction }^{a}\end{array}$ \\
\hline B17 & 280.3 & 109 & 11.54 & 1.969 & borax & 0.173 \\
\hline B08 & 280.5 & 110 & 11.48 & 1.766 & borax & 0.189 \\
\hline B18 & 174.0 & 78 & 11.02 & 1.156 & borax & 0.272 \\
\hline B09 & 40.0 & 27 & 10.32 & 0.459 & borax & 0.499 \\
\hline B10 & 40.0 & 27 & 8.75 & 0.456 & borax & 0.425 \\
\hline B27 & 503.1 & 135 & 8.22 & 1.115 & borax & 0.611 \\
\hline B25 & 195.3 & 83 & 7.58 & 0.942 & borax & 0.183 \\
\hline B23 & 259.5 & 104 & 7.35 & 1.637 & borax & 0.138 \\
\hline B24 & 476.2 & 168 & 5.44 & 1.625 & $\begin{array}{l}\text { sassolite } \\
\text { + sborgite }\end{array}$ & \\
\hline B29 & 140.0 & 39 & 5.91 & 2.190 & sassolite & 0.063 \\
\hline B30 & 331.9 & 88 & 5.48 & 1.254 & sassolite & 0.115 \\
\hline
\end{tabular}

${ }^{a}=$ the amount of $B$ in the mineral divided by the amount of $B$ in the initial solution, calculated using the $B$ contents in the solid phase and in the initial solution.

Table 3. Isotopic data

\begin{tabular}{|c|c|c|c|c|c|c|}
\hline \multirow{2}{*}{$\begin{array}{l}\text { Run } \\
\text { No. }\end{array}$} & \multirow{2}{*}{ Mineral } & \multicolumn{2}{|c|}{ Solution phase } & \multicolumn{2}{|c|}{ Solid phase } & \multirow{2}{*}{$S$} \\
\hline & & ${ }^{11} \mathrm{~B} /{ }^{10} \mathrm{~B}$ & $\delta^{11} \mathrm{~B}$ & ${ }^{11} \mathrm{~B} /{ }^{10} \mathrm{~B}$ & $\delta^{11} \mathrm{~B}$ & \\
\hline B17 & borax & $4.031 \pm 0.009$ & -3.0 & $4.087 \pm 0.009$ & +10.8 & 1.0138 \\
\hline B08 & borax & $4.028 \pm 0.009$ & -4.0 & $4.067 \pm 0.006$ & +5.7 & 1.0097 \\
\hline B18 & borax & $4.040 \pm 0.008$ & -0.9 & $4.087 \pm 0.008$ & +10.8 & 1.0118 \\
\hline B09 & borax & $4.046 \pm 0.003$ & +0.5 & $4.065 \pm 0.009$ & +5.3 & 1.0048 \\
\hline B10 & borax & $4.072 \pm 0.003$ & +7.1 & $4.028 \pm 0.004$ & -3.9 & 0.9890 \\
\hline B27 & borax & $4.056 \pm 0.001$ & +3.0 & $4.033 \pm 0.006$ & -2.7 & 0.9943 \\
\hline B25 & borax & $4.069 \pm 0.006$ & +6.4 & $4.019 \pm 0.004$ & -6.2 & 0.9875 \\
\hline B23 & borax & $4.053 \pm 0.001$ & +2.3 & $4.015 \pm 0.005$ & -7.0 & 0.9907 \\
\hline \multirow[t]{2}{*}{ B24 } & sassolite & $4.038 \pm 0.006$ & -1.4 & $4.052 \pm 0.006$ & +2.0 & 1.0034 \\
\hline & sborgite & & & $4.029 \pm 0.002$ & -3.6 & 0.9978 \\
\hline B29 & sassolite & $4.043 \pm 0.002$ & -0.1 & $4.061 \pm 0.003$ & +4.2 & 1.0044 \\
\hline B30 & sassolite & $4.045 \pm 0.003$ & +0.3 & $4.047 \pm 0.004$ & +0.9 & 1.0006 \\
\hline
\end{tabular}

phase to the solid phase ranges from 0.063 to 0.611. Borax $\left(\mathrm{Na}_{2}\left[\mathrm{~B}_{4} \mathrm{O}_{5}(\mathrm{OH})_{4}\right] \cdot 8 \mathrm{H}_{2} \mathrm{O}\right)$, sassolite $\left(\mathrm{B}(\mathrm{OH})_{3}\right)$ or sborgite $\left(\mathrm{Na}\left[\mathrm{B}_{5} \mathrm{O}_{6}(\mathrm{OH})_{4}\right] \cdot 3 \mathrm{H}_{2} \mathrm{O}\right)$ was precipitated. Borax was formed from the solutions with higher $\mathrm{pH}$ values, while sassolite was from the solutions with lower $\mathrm{pH}$ values, irrepective of the $\mathrm{B} / \mathrm{Na}$ ratio of the initial solution. Sborgite was found only in B-24, together with predominant sassolite. The purity of the borax and sassolite was measured by the acidbase titration method and found to be $100 \%$ within experimental error. In addition, the X-ray powder diffraction patterns of these minerals showed that the impurity levels were below $1 \%$.
Chloride ions were not found in the minerals.

All the isotopic data are given by both ${ }^{11} \mathrm{~B} /{ }^{10} \mathrm{~B}$ isotopic ratios and $\delta^{11} \mathrm{~B}$ values. $\delta^{11} \mathrm{~B}$ is defined as $\delta^{11} \mathrm{~B}=\left[\left({ }^{11} \mathrm{~B} /{ }^{10} \mathrm{~B}\right)_{\text {sample }} /\left({ }^{11} \mathrm{~B} /{ }^{10} \mathrm{~B}\right)_{\text {standard }}-1\right]$ $\cdot 1000$, where the NBS SRM 951 boric acid standard is taken as the standard. Our ${ }^{11} \mathrm{~B} /{ }^{10} \mathrm{~B}$ value of the NBS SRM 951 boric acid is in agreement with the certified value of 4.0436 (Catanzaro et al., 1970). The fractionation factor, $S$, of boron isotopes between the solid and solution phases in equilibrium is defined as $S=\left({ }^{11} \mathrm{~B} /{ }^{10} \mathrm{~B}\right)_{\text {mineral }} /$

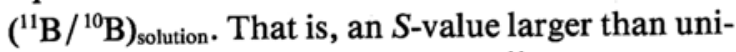
ty means that the heavier isotope, ${ }^{11} \mathrm{~B}$, is preferentially fractionated into the solid (mineral) phase 
and vice versa. Figure 1 plots the $S$ values against the final $\mathrm{pH}$ values. The isotopic results are summarized as follows:

(1) For the runs where borax was synthesized (borax system), the fractionation factor increases with the $\mathrm{pH}$ of the solution. The same seems to hold for the sassolite system with less certainty.

(2) A cross-over point, a point at which $S=1$, exists at about $\mathrm{pH}=9.5$ in the borax system. Such a point is not observed for the sassolite system; the $S$-value of the sassolite system is always larger than unity within the experimental $\mathrm{pH}$ range.

(3) The extrapolation of the fractionation factor ( $S$ values) for borax to lower $\mathrm{pH}$ region, where sassolite formed, indicates that sassolites has larger $S$ values against the solution than does borax.

(4) Although only a single comparison is available, sassolite shows a larger fractionation factor than sborgite which formed from the same solution.

\section{Qualitative EXPLANATION OF THE OBSERVED BORON ISOTOPE FraCtIONATION}

The boron isotope fractionation systematics found in the present study are qualitatively explained by the theory of equilibrium isotope effects (Bigeleisen and Mayer, 1947) based on the ${ }^{11} \mathrm{~B}$-to- ${ }^{10} \mathrm{~B}$ isotopic RPFRs of boron species involved in the present systems. When two chemical species are isotopically in equilibrium, the heavier isotope is preferentially fractionated into the species with larger RPFR value.

When two isotopes are distributed between two phases with boron species being isotopically in equilibrium, the fractionation factor, $S$, is given in terms of the RPFRs of the boron species and their mole fractions as (Kakihana and Aida, 1973)

$$
\ln S=-\ln \left(\Sigma x_{s} f_{s}\right)+\ln \left(\Sigma y_{t} g_{t}\right),
$$

where $f_{s}$ is the RPFR of the species $s$ in the first phase, $x_{s}$ its mole fraction, $g_{t}$ the RPFR of the species $t$ in the second phase, $y_{t}$ its mole fraction

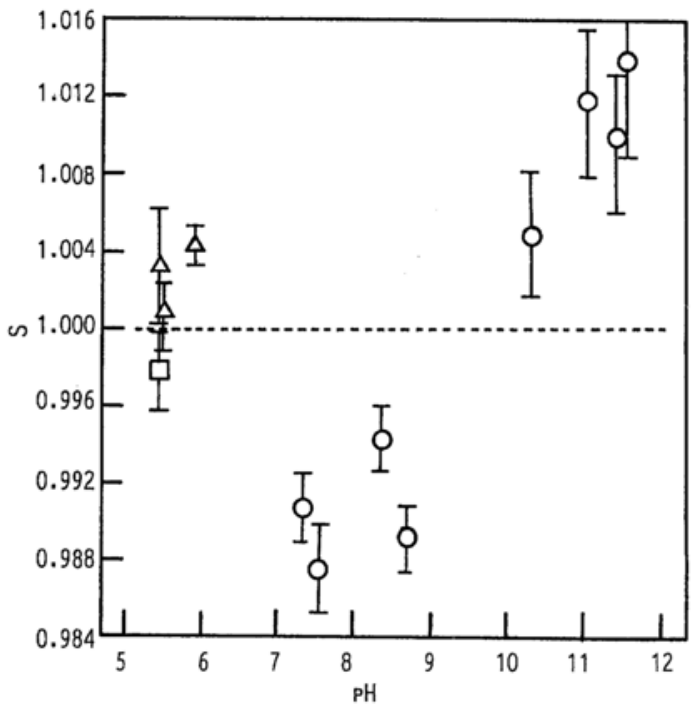

Fig. 1. Plot of the fractionation factor (S) against the $\mathrm{pH}$ of the solution. $\mathrm{O}=$ borax; $\triangle=$ sassolite; $\square=$ sborgite.

and $\Sigma x_{s}=\Sigma y_{t}=1$. The symmetry numbers are neglected in Eq. (1) for simplicity.

The solution phase in the present systems is concentrated boric acid solutions. The boron species include not only monomeric species, $\mathrm{B}(\mathrm{OH})_{3}$ and $\mathrm{B}(\mathrm{OH})_{4}^{-}$, but also polyborates such as $\mathrm{B}_{3} \mathrm{O}_{3}(\mathrm{OH})_{4}^{-}$and $\mathrm{B}_{3} \mathrm{O}_{3}(\mathrm{OH})_{5}^{2-}$ (Ingri et al., 1957; Spessard, 1970). Their concentrations depend on the total boron concentration, the $\mathrm{pH}$ of the solution, temperature etc. The RPFR values of the monomeric species have been calculated (Kakihana et al., 1977) at several temperatures using vibrational $\mathbf{F}$ matrices which best reproduce the observed vibrational frequencies of these species. Since satisfactory vibrational data on polyborate anions have not yet been reported, the RPFRs of these species based on vibrational analysis are not available. However, it is possible to approximate the ln (RPFR) value of a polyborate by the weighted sum of the $\ln$ (RPFR) values of monomeric species (Oi et al., 1989). When a polyborate anion consists of $n$ $\mathrm{BO}_{3}$ planar triangles and $m \mathrm{BO}_{4}$ tetrahedra with boron atoms at the center in both units and with some of the oxygen atoms in $\mathrm{BO}_{3}$ and $\mathrm{BO}_{4}$ units being replaced by $\mathrm{OH}$ group, the RPFR of the 
polyanion can be approximated as

$\ln f=[n /(n+m)] \ln f_{\mathrm{B} 3}+[m /(n+m)] \ln f_{\mathrm{B} 4}$,

where $f, f_{\mathrm{B} 3}$ and $f_{\mathrm{B} 4}$ are the RPFRs of the polyborate, $\mathrm{BO}_{3}$ and $\mathrm{BO}_{4}$, respectively. For instance, since the $\mathrm{B}_{3} \mathrm{O}_{3}(\mathrm{OH})_{5}^{2-}$ species consists of one $\mathrm{BO}_{3}$ unit and two $\mathrm{BO}_{4}$ units, its RPFR is given as $\ln f=(1 / 3) \ln f_{\mathrm{B} 3}+(2 / 3) \ln f_{\mathrm{B} 4}$. Since all polyborate anions existing in the solution phase can be divided into the two monomeric parts, the RPFR of the solution phase is expressed as $x f_{\mathrm{B} 3}+(1-x) f_{\mathrm{B} 4}$ where $x$ is the mole fraction of the $\mathrm{B}(\mathrm{OH})_{3}$ species in the solution phase. Of course, the $x$ value is dependent on such parameters as the total boron concentration and the $\mathrm{pH}$ of the solution.

A similar consideration can be applied to the solid phase; the RPFR of the solid phase is given in the form of $y f_{\mathrm{B} 3}+(1-y) f_{\mathrm{B} 4}$ where $y$ is the mole fraction of the $\mathrm{B}(\mathrm{OH})_{3}$ species in the solid phase. The $y$ value is determined by the crystal structure of the mineral concerned and is 0.5 for borax, 0.8 for sborgite and 1.0 for sassolite. The general expression (1) is then simplified to

$$
\begin{aligned}
\ln S= & \ln \left[y f_{\mathrm{B} 3}+(1-y) f_{\mathrm{B} 4}\right]-\ln \left[x f_{\mathrm{B} 3}+(1-x) f_{\mathrm{B} 4}\right] \\
= & \ln \left[y f_{\mathrm{B} 3} / f_{\mathrm{B} 4}+(1-y)\right]-\ln \left[x f_{\mathrm{B} 3} / f_{\mathrm{B} 4}\right. \\
& +(1-x)] .
\end{aligned}
$$

In the derivation of Eq. (3), we assumed that the RPFR value of a boron species is the same in the two phases. That is, the boron isotope effect accompanying phase change is negligible. Appropriateness of this assumption is supported by the fact that no boron isotope effect has been observed in cation exchange chromatography of $\mathrm{B}(\mathrm{OH})_{3}$ (Kakihana et al., 1977) or in anion exchange chromatography of $\mathrm{B}(\mathrm{OH})_{4}^{-}$(Urgell et al., 1964) within experimental errors. Also, no boron isotope fractionation was observed within experimental error in our experiment in which sassolite was equilibrated with a solution containing $\mathrm{B}(\mathrm{OH})_{3}$ as the only boron species. The quantity $f_{\mathrm{B} 3} / f_{\mathrm{B} 4}$ in Eq. (3) is the equilibrium constant, $K$, of the boron isotope exchange reaction between $\mathrm{B}(\mathrm{OH})_{3}$ and $\mathrm{B}(\mathrm{OH})_{4}^{-}$,

$$
{ }^{10} \mathrm{~B}(\mathrm{OH})_{3}+{ }^{11} \mathrm{~B}(\mathrm{OH})_{4}^{-}={ }^{11} \mathrm{~B}(\mathrm{OH})_{3}+{ }^{10} \mathrm{~B}(\mathrm{OH})_{4}^{-} .
$$

The value of $K$ is larger than unity at any temperature and has been calculated to be 1.0194 at $25^{\circ} \mathrm{C}$ (Kakihana et al., 1977). By replacing $f_{\mathrm{B} 3} / f_{\mathrm{B} 4}$ by $K$ in Eq. (3) and rearranging the resultant equation, we obtain

$$
S-1=(y-x)(K-1) /[x(K-1)+1] .
$$

This equation provides a basis for understanding the observations (1)-(4) summarized in RESULTS. For a given mineral (i.e., for a fixed $y$ value), a larger $x$-value (which implies a lower $\mathrm{pH}$ value) gives a smaller $S$-value (observation (1) in RESULTS). This is independent of the type of mineral. When the mineral is sassolite, $y=1$ and hence $S-1 \geqq 0 ;{ }^{11} \mathrm{~B}$ is always preferentially fractionated into the solid phase (observation (2)). When the mineral is borax, $y=1 / 2$, and $S-1 \geqq 0$ for $y \geqq x$ and $S-1<0$ for $y<x$. Thus, there exists a cross-over point at $y=x=1 / 2$ (observation (2)). For a common $\mathrm{pH}$ value of the solution (i.e., for a fixed $x$ value), a mineral with a larger $y$-value gives a larger $S$ value. Hence, $S_{\text {sassolite }}>S_{\text {sborgite }}>S_{\text {borax }}$ at a given pH (observations (3) and (4)).

The above discussion is schematically drawn for the case of borax in Fig. 2. The boron isotopic composition of the initial solution is fixed irrespective of its $\mathrm{pH}$ value. However, the ${ }^{11} \mathrm{~B} /{ }^{10} \mathrm{~B}$ ratios of the $\mathrm{B}(\mathrm{OH})_{3}$ and $\mathrm{B}(\mathrm{OH})_{4}^{-}$species in the solution are dependent on the $\mathrm{pH}$ of the solution, with the ${ }^{11} \mathrm{~B} /{ }^{10} \mathrm{~B}$ ratio of $\mathrm{B}(\mathrm{OH})_{3}$ being always $K$ times larger than that of $\mathrm{B}(\mathrm{OH})_{4}^{-}$. When the $\mathrm{pH}$ is high, the mole fraction of $\mathrm{B}(\mathrm{OH})_{4}^{-}(=1-x)$ is much larger than that of $\mathrm{B}(\mathrm{OH})_{3}(=x)$. The isotopic ratio of $\mathrm{B}(\mathrm{OH})_{4}^{--}$is hence a little lower than but is very close to that of the total boron in the solution while the isotopic ratio of $\mathrm{B}(\mathrm{OH})_{3}$ is about $K$ times larger than that of the solution. If borax is deposited from this solution with the 1:1 mole ratio of $\mathrm{B}(\mathrm{OH})_{3}$ and $\mathrm{B}(\mathrm{OH})_{4}^{-}$species, the formed borax shows a large ${ }^{11} \mathrm{~B} /{ }^{10} \mathrm{~B}$ ratio. On the contrary, if the $\mathrm{pH}$ of the initial solution is low, $\mathrm{B}(\mathrm{OH})_{3}$ is the major species in the solution. The ${ }^{11} \mathrm{~B} /{ }^{10} \mathrm{~B}$ 


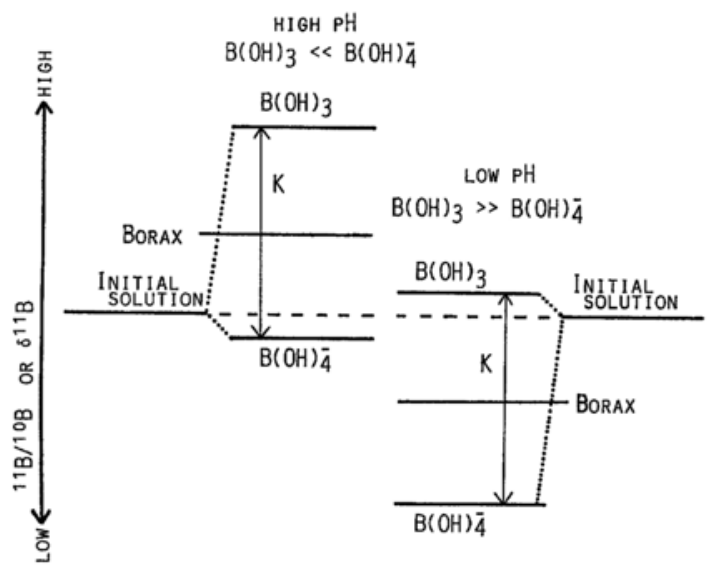

Fig. 2. Schematic presentation of boron isotope fractionation in borax formation.

value of $\mathrm{B}(\mathrm{OH})_{3}$ is a little higher than but is very close to that of the total solution, while the ${ }^{11} \mathrm{~B} /{ }^{10} \mathrm{~B}$ ratio of $\mathrm{B}(\mathrm{OH})_{4}^{-}$is about $K$ times lower than that of the solution. If borax is formed from this solution with the mole ratio of $1: 1$ of $\mathrm{B}(\mathrm{OH})_{3}$ and $\mathrm{B}(\mathrm{OH})_{4}^{-}$, its ${ }^{11} \mathrm{~B} /{ }^{10} \mathrm{~B}$ ratio becomes small. When the amount of $\mathrm{B}(\mathrm{OH})_{3}$ is the same as that of $\mathrm{B}(\mathrm{OH})_{4}^{-}$in the initial solution, there is no boron isotope effect accompanying borax formation $(S=1)$.

\section{Estimation of $K$ VALUes on the Basis OF THE EQUILIBRIUM ISOTOPE Distribution between Two Phases}

In Eq. (5), the $S$ is experimentally determined. The $y$ has a fixed value for a given boron mineral. If the total boron concentration and the $\mathrm{pH}$ of the solution are given, the $x$ is calculable using stability constants of polyborate anions in the solution in which the polyborates are assumed to be composed of the monomeric species, $\mathrm{B}(\mathrm{OH})_{3}$ and $\mathrm{B}(\mathrm{OH})_{4}^{-}$. Thus, the $K$-value can be estimated for each run of the experiments using Eq. (5). The results of the estimation are summarized in Table 4. The type of polyborate anions existing in the solution and their stability constants are cited from Spessard (1970):

$\mathrm{B}(\mathrm{OH})_{3}+\mathrm{H}_{2} \mathrm{O}=\mathrm{B}(\mathrm{OH})_{4}^{-}+\mathrm{H}^{+}$
Table 4. $K$ values estimated using Eq. (5)

\begin{tabular}{llcc}
\hline $\begin{array}{l}\text { Run } \\
\text { No. }\end{array}$ & Mineral & $\begin{array}{c}\text { Mole fraction of } \mathrm{B}(\mathrm{OH})_{3} \\
\text { in solution phase }\end{array}$ & $K$ \\
\hline B17 & borax & 0.244 & 1.0547 \\
B08 & borax & 0.242 & 1.0379 \\
B18 & borax & 0.290 & 1.0571 \\
B09 & borax & 0.344 & 1.0309 \\
B10 & borax & 0.656 & 1.0739 \\
B27 & borax & 0.715 & 1.0270 \\
B25 & borax & 0.791 & 1.0445 \\
B23 & borax & 0.795 & 1.0323 \\
B29 & sassolite & 0.853 & 1.0307 \\
B30 & sassolite & 0.904 & 1.0063 \\
\hline
\end{tabular}

${ }^{a}$ Estimated at the final $\mathrm{pH}$ using stability constants by Spessard (1970).

$$
K_{1}=5.06 \cdot 10^{-10}
$$

$3 \mathrm{~B}(\mathrm{OH})_{3}=\mathrm{B}_{3} \mathrm{O}_{3}(\mathrm{OH})_{4}^{-}+\mathrm{H}^{+}+2 \mathrm{H}_{2} \mathrm{O}$

$$
K_{13}=1.94 \cdot 10^{-7}
$$

$3 \mathrm{~B}(\mathrm{OH})_{3}=\mathrm{B}_{3} \mathrm{O}_{3}(\mathrm{OH})_{5}^{2-}+2 \mathrm{H}^{+}+\mathrm{H}_{2} \mathrm{O}$

$$
K_{23}=3.83 \cdot 10^{-11}
$$

$4 \mathrm{~B}(\mathrm{OH})_{3}=\mathrm{B}_{4} \mathrm{O}_{5}(\mathrm{OH})_{4}^{2-}+2 \mathrm{H}^{+}+3 \mathrm{H}_{2} \mathrm{O}$

$$
K_{24}=1.82 \cdot 10^{-15}
$$

$5 \mathrm{~B}(\mathrm{OH})_{3}=\mathrm{B}_{5} \mathrm{O}_{6}(\mathrm{OH})_{4}^{-}+\mathrm{H}^{+}+5 \mathrm{H}_{2} \mathrm{O}$

$$
K_{15}=2.17 \cdot 10^{-6}
$$

(The concentrations of the chemical species are given in the unit of $\mathrm{mol} / \mathrm{dm}^{3}$.). The calculated $K$-value varies from 1.0063 to 1.0739 and the arithmetic average of ten data is $1.0395 \pm 0.0188$. This value is larger than the theoretical value of 1.0194 at $25^{\circ} \mathrm{C}$ which was obtained based on spectroscopic data of $\mathrm{B}(\mathrm{OH})_{3}$ and $\mathrm{B}(\mathrm{OH})_{4}^{-}$ (Kakihana et al., 1977).

\section{Estimation of $\boldsymbol{S}$ Values by Computer Simulation OF Mineral Formation Processes}

In the above discussion, the process by which minerals are precipitated has not been taken into consideration; all the species were assumed to be isotopically in equilibrium with each other. It is possible that the observed fractionation factor is more or less dependent on how minerals are 
synthesized. In this context, we carried out a computer simulation to reproduce the mineral formation that would have occurred in our experiments. In the simulation, we assumed that: 1) a mineral is gradually deposited from the initial solution,

2) during the mineral deposition, the mole ratio of the $\mathrm{B}(\mathrm{OH})_{3}$ and $\mathrm{B}(\mathrm{OH})_{4}^{-}$species is kept unaltered and the isotopic equilibrium between the two boron species is always maintained in the solution phase,

3) the polyborate anion in the mineral to be deposited is formed in the solution phase by the combination of $\mathrm{B}(\mathrm{OH})_{3}$ and $\mathrm{B}(\mathrm{OH})_{4}^{-}$with the same mole ratio as that in the mineral, and there is no boron isotope fractionation accompanying the transfer of the polyborate anion from the solution phase to the solid phase, and

4) there is no species change from $\mathrm{B}(\mathrm{OH})_{3}$ to $\mathrm{B}(\mathrm{OH})_{4}^{-}$or vice versa after they have been transferred to the solid phase.

From the first and second assumptions, it follows that the boron isotopic ratio of the mineral (and also that of the solution) is time dependent; an aliquot deposited earlier has a different ${ }^{11} \mathrm{~B} /{ }^{10} \mathrm{~B}$ value from that of an aliquot deposited later. And it is our major premise that the experimentally observed boron isotope effect is an equilibrium isotope effect but not a kinetic one.

In the computer program used, mineral deposition was assumed to occur in $l$ steps, the amount of boron transferred from the solution phase to the mineral phase being the same in every step. The $l$-value was increased until the $S$ value converged. The ${ }^{11} \mathrm{~B} /{ }^{10} \mathrm{~B}$ ratios in the mineral, $\left({ }^{11} \mathrm{~B} /{ }^{10} \mathrm{~B}\right)_{\min , k}$, and in the solution, $\left({ }^{11} \mathrm{~B} /{ }^{10} \mathrm{~B}\right)_{\text {sol, } k}$, in the $k$-th step are given as

$$
\left({ }^{11} \mathrm{~B} /{ }^{10} \mathrm{~B}\right)_{\min , k}=\left(2 k-\Sigma R_{i}\right) / \Sigma R_{i} \text {, }
$$

and

$$
\begin{aligned}
\left({ }^{11} \mathrm{~B} /{ }^{10} \mathrm{~B}\right)_{\mathrm{sol}, k}= & {\left[1-R_{0}-\Delta\left(2 k-\Sigma R_{i}\right)\right] } \\
& /\left(R_{0}-\Delta \Sigma R_{i}\right),
\end{aligned}
$$

respectively. In Eqs. (6) and (7), $R_{i}=R_{3, i}+R_{4, i}$, $R_{3, i}$ is the isotopic mole fraction of ${ }^{10} \mathrm{~B}$ in the
Table 5. Comparison of experimental and calculated $S$ values for borax

\begin{tabular}{lcccc}
\hline \multirow{2}{*}{$\begin{array}{l}\text { Run } \\
\text { No. }\end{array}$} & $\begin{array}{c}\text { Experimental } \\
S \text { value }\end{array}$ & \multicolumn{3}{c}{ Calculated $S$ value } \\
\cline { 3 - 5 } & & $K=1.0194^{\mathrm{a}}$ & $K=1.050^{\mathrm{a}}$ & $K=1.050^{\mathrm{b}}$ \\
\hline B17 & 1.0138 & 1.0054 & 1.0136 & 1.0218 \\
B08 & 1.0097 & 1.0045 & 1.0113 & 1.0218 \\
B18 & 1.0118 & 1.0047 & 1.0119 & 1.0214 \\
B09 & 1.0048 & 1.0032 & 1.0081 & 1.0225 \\
B10 & 0.9890 & 0.9967 & 0.9916 & 0.9934 \\
B27 & 0.9943 & 0.9953 & 0.9881 & 0.9869 \\
B25 & 0.9875 & 0.9943 & 0.9855 & 0.9858 \\
B23 & 0.9907 & 0.9945 & 0.9861 & 0.9862 \\
\hline
\end{tabular}

${ }^{a}$ With stability constants of Spessard (1970).

${ }^{b}$ With stability constants of Ingri et al. (1957).

$\mathrm{B}(\mathrm{OH})_{3}$ species of the solution phase in the $i$-th step, $R_{4, i}$ that of $\mathrm{B}(\mathrm{OH})_{4}^{-}, R_{0}$ the isotopic mole fraction of ${ }^{10} \mathrm{~B}$ in the initial solution, $\Delta$ the ratio of the amount of boron transferred in one step to the total amount of boron in the initial solution, and the summations are taken from $i=0$ to $k-1 . S$ is given as $\left({ }^{11} \mathrm{~B} /{ }^{10} \mathrm{~B}\right)_{\min , l} /\left({ }^{11} \mathrm{~B} /{ }^{10} \mathrm{~B}\right)_{\text {sol }, l}$.

The $S$-values obtained by the simulation for borax are given for $K=1.0194$ and 1.050 in Table 5, together with the experimental results. In general, a small $K$-value yields a small deviation of $S$-value from unity. Evidently from Table $5, K=1.0194$ is too small to reproduce the experimentally obtained $S$-values and the most favorable $K$-value for the present experiments seems to be between 1.03 and 1.05 . This result is consistent with that indicated in the preceding section.

The analyses given above suggest that the value of $K$ in Eq. (4) is larger than that theoretically obtained at $25^{\circ} \mathrm{C}$ on the basis of vibrational frequency data. There is some other experimental evidence that the $K$-value is larger than 1.019-1.020 at ambient temperatures. Spivack et al. (1987) obtained 1.028 and 1.026 as values of the boron isotope fractionation factor at $21^{\circ} \mathrm{C}$ between boron adsorbed in a sediment and boron in the supernatant which was supposed to be isotopically in equilibrium with the sediment. This result can be interpreted as indicating that 1.026 or 1.028 is the minimum value of $K$ at $21^{\circ} \mathrm{C}$, because boron exists not only as $\mathrm{B}(\mathrm{OH})_{4}^{-}$ 
but also as $\mathrm{B}(\mathrm{OH})_{3}$ in the sediment. Palmer et al. (1987) obtained $K=1.032 \pm 0.002$ for boron isotope exchange between clay minerals and supernatants at $25^{\circ} \mathrm{C}$. A $K$-value observed between boron in aqueous solution and boron adsorbed in activated carbon is larger than 1.0194 at room temperature (Nomura et al., 1990). Some of our unpublished data on separation factors in ion-exchange chromatographic separation of boron isotopes also indicate that $K$ in Eq. (4) should be larger than 1.0194 at $25^{\circ} \mathrm{C}$. In spite of these studies and our present results, we are hesitant in concluding an exact $K$-value at $25^{\circ} \mathrm{C}$ primarily because of uncertainties in the estimation of the mole ratios of $\mathrm{B}(\mathrm{OH})_{3}$ and $\mathrm{B}(\mathrm{OH})_{4}^{-}$in the initial solutions. As mentioned before, different stability constants result in different $K$ values, and in our experiments, ionic strengths of the initial solutions just before mineral depositions were uncontrolled (it was in fact impossible). For comparison, the $S$-values calculated for $K=1.050$ using the stability constants of Ingri et al. (1957) are listed in the last column of Table 5. These values are in general larger than those calculated using the stability constants of Spessard (1970).

In the present study, initial solutions are limited to boric acid-sodium hydroxide solutions, and hence minerals obtained are only $\mathrm{Na}$ borates and sassolite. By using different cations in initial solutions, a variety of boron minerals will be synthesized. Such synthetic experiments are desired not only for obtaining more reliable $K$-value in Eq. (4) but also for knowing quantitative relationship between the fractionation factor and the structure of minerals (Oi et al., 1989).

The present study showed that the fractionation factor is very strongly dependent on the $\mathrm{pH}$ of the solution from which mineral is deposited. This, for instance, suggests the possibility that the $\mathrm{pH}$ of a palaeo-natural water from which a boron mineral formed can be determined by knowing the ${ }^{11} \mathrm{~B} /{ }^{10} \mathrm{~B}$ ratio of the mineral, because $K$ is not sensitive to temperature as shown by Palmer et al. (1987).

\section{CONClusions}

The findings of this study are summarized as follows:

(1) The boron isotopic composition of a boron mineral deposited from aqueous boric acid-sodium hydroxide solution is heavily dependent on the $\mathrm{pH}$ of the solution. In higher $\mathrm{pH}$ condition the heavier isotope, ${ }^{11} \mathrm{~B}$, is more preferentially fractionated into the solid phase. This tendency is independent of the type of mineral formed (borax or sassolite).

(2) At a given $\mathrm{pH}$ of the initial solution, the degree of "B-enrichment increases in the order of borax, sborgite and sassolite.

(3) (1) and (2) are consistent with theoretical predictions.

(4) The present experimental results suggest that the equilibrium constant value of Eq. (4) at $25^{\circ} \mathrm{C}$ is larger than what has been theoretically obtained (1.0194).

Acknowledgments-We acknowledge Professor M. Okamoto of Tokyo Institute of Technology for offering the use of a Varian MAT CH-5 mass spectrometer and Dr. M. Nomura of T.I.T. for his assistance in mass spectrometric measurements of boron isotopic ratios.

\section{REFERENCES}

Bigeleisen, J. and Mayer, M. G. (1947) Calculation of equilibrium constants for isotopic exchange reactions. J. Chem. Phys. 15, 261-267.

Catanzaro, E. S., Champoin, C. E., Garner, E. L., Marinenko, G., Sapenfield, K. M. and Shields, W. R. (1970) NBS Spec. Publ. (US) No. 260-17.

Ingri, N., Lagerstrom, G., Fryman, M. and Sillen, L. G. (1957) Equilibrium studies of polyanions II Polyborates in $\mathrm{NaClO}_{4}$ medium. Acta Chem. Scand. 11, 1034-1058.

Ishikawa, T. and Nakamura, E. (1989) Boron isotope geochemistry and cosmochemistry. Chikyukagaku (Geochemistry) 23, 23-34 (in Japanese).

Kakihana, H. and Aida, M. (1973) Distribution of isotopes between two phases. Bull. Tokyo Inst. Technol. 116, 39-52.

Kakihana, H., Kotaka, M., Satoh, S., Nomura, M. and Okamoto, M. (1977) Fundamental studies on the ion-exchange separation of boron isotopes. 
Bull. Chem. Soc. Jpn. 50, 158-163.

Kanzaki, T., Yoshida, N., Nomura, M., Kakihana, H. and Ozawa, T. (1979) Boron isotopic composition of fumaloric condensates and sassolites from Satsuma Iwo-jima, Japan. Geochim. Cosmochim. Acta 43, 1859-1863.

Nomura, M., Okamoto, M. and Kakihana H. (1973) Determination of boron isotopic ratio by the surface ionization method. Shitsuryo Bunseki (Mass Spectrometry) 21, 277-281 (in Japanese).

Nomura, M., Kanzaki, T., Ozawa, T., Okamoto, M. and Kakihana, H. (1982) Boron isotopic composition of fumaloric condensates from some volcanoes in Japan island arcs. Geochim. Cosmochim. Acta 46, 2403-2406.

Nomura, M., Fujii, Y. and Okamoto, M. (1990) The isotopic ratios of boron in coals. Shitsuryo Bunseki (Mass Spectrometry) 38, 95-100 (in Japanese).

Oi, T., Nomura, M., Musashi, M., Ossaka, T., Okamoto, M. and Kakihana H. (1989) Boron isotopic compositions of some boron minerals. Geochim. Cosmochim. Acta 53, 3189-3195.

Oi, T., Musashi, M., Nomura, M., Ossaka, T., Okamoto, M. and Kakihana, H. (1991) Influence of sea water on boron isotopic ratios of hot spring waters in Japan. Bull. Soc. Sea Water Sci., Jpn. 45, 29-34 (in Japanese).

Palmer, M. R., Spivack, A. J. and Edmond, J. M. (1987) Temperature and $\mathrm{pH}$ controls over isotopic fractionation during adsorption of boron on marine clay. Geochim. Cosmochim. Acta 51, 23192323.

Palmer, M. R. and Slack J. F. (1989) Boron isotopic composition of tourmaline from massive sulfide deposits and tourmalinites. Contrib. Mineral. Petrol. 103, 434-451.

Slack, F. J., Palmer, M. R. and Stevens, B. P. J. (1989) Boron isotope evidence for the involvement of non-marine evaporites in the origin of the Broken Hill ore deposits. Nature 342, 913-916.

Spessard J. E. (1970) Investigations of borate equilibria in neutral salt solutions. J. Inorg. Nucl. Chem. 32, 2607-2613.

Spivack, A. J. and Edmond, J. M. (1987) Boron isotope exchange between seawater and the ocean crust. Geochim. Cosmochim. Acta 51, 1033-1043.

Spivack, A. J., Palmer, M. R. and Edmond, J. M. (1987) The sedimentary cycle of the boron isotopes. Geochim. Cosmochim. Acta 51, 1939-1949.

Swihart, G. H., Moore, P. B. and Calls, E. L. (1986) Boron isotopic composition of marine and nonmarine evaporite borates. Geochim. Cosmochim. Acta 50, 1297-1301.

Urgell, M. M., Iglesias, J., Casas, J., Saviron, J. M. and Quintanilla, M. (1964) The production of stable isotopes in Spain. Third United Nations International Conference on the Peaceful Uses of Atomic Energy, A/CONF.28/P/491, Spain. 